\title{
Comunicação
}

[Communication]

\section{Cinética ruminal de dietas contendo farelo de mamona destoxificado}

\author{
[Ruminal kinetics of diets containing detoxicated castor bean meal] \\ D.R. Menezes ${ }^{1}$, R.G. Costa $^{2}$, G.G.L. Araújo ${ }^{3}$, L.G.R. Pereira ${ }^{4}$, A.C.B. Nunes ${ }^{1}$ \\ L.T. Henrique ${ }^{5}$, R.T.S. Rodrigues ${ }^{6}$ \\ ${ }^{1}$ Universidade Federal do vale do São Francisco - Petrolina, PE \\ ${ }^{2}$ Universidade Federal da Paraíba - Bananeiras, PB \\ ${ }^{3}$ EMBRAPA Semiárido - Petrolina, PE \\ ${ }^{4}$ EMBRAPA Gado de Leite - Juiz de Fora, MG \\ ${ }^{5}$ Universidade Federal da Paraíba - Areia, PB \\ ${ }^{6}$ Universidade Federal de Viçosa - Viçosa, MG
}

A cadeia produtiva do biodiesel é responsável por grandes quantidades de resíduos que se tornam problemas ambientais passíveis de multa e encargos com o seu armazenamento. Dessa forma, existe a necessidade de um destino adequado e sustentável para esses materiais. Uma alternativa importante é a utilização desses resíduos na alimentação animal, principalmente na região do semiárido brasileiro, devido às constantes estiagens. Entretanto, a presença de princípios tóxicos e alergênicos, normalmente presentes nos resíduos do biodiesel, tem dificultado sua utilização como alimentos alternativos (Severino, 2005).

A ricina constitui-se no principal composto tóxico presente na mamona e exerce seu mecanismo de toxidez por meio da inibição da síntese ribossomal e, por consequência, estagnação na síntese proteica intracelular, causando, posteriormente, a morte da célula. Durante o processo de extração do óleo da semente da mamona para a obtenção do biodiesel, a ricina remanesce na torta ou no farelo, pelo fato de não apresentar solubilidade em lipídeos (Oliveira et al., 2010a).

Os ruminantes podem suportar quantidades de farelo de mamona sem destoxificação de 100 a $150 \mathrm{~g} / \mathrm{kg}$ de matéria seca sem apresentar respostas à intoxicação, como, por exemplo, aumento nos teores de enzimas hepáticas ou até mesmo morte.

Recebido em 17 de julho de 2013

Aceito em 18 de novembro de 2014

E-mail: daniel.menezes@univasf.edu.br
Esse fato sugere que, por ser uma proteína, a ricina pode ser hidrolisada parcial ou totalmente durante o processo fermentativo no rúmen (Oliveira et al., 2010b).

A destoxificação do farelo de mamona pode ser capaz de destruir completamente a ricina e, dessa forma, o seu uso em dietas para ruminantes torna-se seguro. Entretanto, o processo de destoxificação pode reduzir os teores de nutrientes, principalmente de proteínas, decrescendo a qualidade nutricional das dietas que compõem o farelo em destaque (Anandan $e t$ al., 2005).

Dessa forma, objetivou-se avaliar a cinética de produção de gases e da degradação ruminal do farelo de soja, farelo de mamona, destoxificado e sem destoxificação, e de dietas contendo farelo de mamona destoxificado em substituição ao farelo de soja.

O experimento foi realizado no Setor de Nutrição Animal e no Laboratório de Produção de Gases da Embrapa Semiárido, em Petrolina, Pernambuco. As dietas experimentais foram compostas por $40 \%$ de feno da capim buffel cv biloella (Cenchrus ciliaris L) e $60 \%$ de concentrado composto por milho em grão moído (MG), ureia, farelo de soja (FS) e farelo de mamona destoxificado (FM). Os tratamentos foram caracterizados pela substituição do FS pelo FM em 15; 30 e $45 \%$, e o tratamento 
testemunha não teve inclusão do FM. As dietas experimentais foram formuladas de acordo com exigências do NRC (2007) para a obtenção de ovinos com $30 \mathrm{~kg}$ de peso vivo e ganhos de peso diários de $200 \mathrm{~g}$.

O FM foi adquirido da usina Brasil Ecodiesel, situada no município de Iraquara, Bahia, e transportado à Embrapa Semiárido, onde foi destoxificado utilizando-se protocolo modificado de Anandan et al. (2005) com hidróxido de cálcio $\left(\mathrm{Ca}(\mathrm{OH})_{2}\right)$ diluído em água na proporção de $9 \mathrm{~L}$ de água/kg de $\mathrm{Ca}(\mathrm{OH})_{2}$, sendo $60 \mathrm{~g}$ de $\mathrm{Ca}(\mathrm{OH})_{2} / \mathrm{kg}$ de FM. Após o tratamento, o FM foi acondicionado em tambor de polietileno de 200L por $24 \mathrm{~h}$ e, posteriormente, seco ao sol por $12 \mathrm{~h}$.
Os alimentos e as dietas foram moídos em moinho de faca tipo Willey, provido de peneiras com crivos de $2 \mathrm{~mm}$ de diâmetro. Após esse procedimento, os alimentos e as dietas foram levados ao Laboratório de Nutrição Animal da Embrapa (Petrolina, PE) para as avaliações bromatológicas. Foram procedidas análises bromatológicas nos ingredientes e dietas de acordo com o descrito em Silva e Queiroz (2002). Os carboidratos totais (CHOT) e os carboidratos não fibrosos (CNF) foram estimados de acordo com Sniffen et al. (1992) e Mertens (1997), respectivamente. As composições bromatológicas dos alimentos e das dietas são apresentadas nas Tabelas 1 e 2.

Tabela 1. Composição química do feno de buffel (FB), milho em grão moído (MG), farelo de soja (FS) e farelo de mamona destoxificado (FM)

\begin{tabular}{lcccc}
\hline \multirow{2}{*}{ Nutriente (\%) } & \multicolumn{4}{c}{ Ingredientes } \\
\cline { 2 - 5 } & FB & MG & FS & FM \\
\hline Matéria seca \% & 92,5 & 88,3 & 90,7 & 92,0 \\
Matéria orgânica* & 83,5 & 86,8 & 84,2 & 81,0 \\
Matéria mineral* & 9,0 & 1,5 & 6,5 & 11,0 \\
Proteína bruta* & 8,0 & 9,5 & 50,2 & 25,3 \\
Extrato etéreo* & 3,3 & 3,7 & 2,1 & 4,0 \\
Carboidratos totais* & 77,7 & 78,3 & 36,3 & 55,7 \\
Carboidratos não fibrosos* & 1,2 & 62,7 & 2,3 & 1,1 \\
Fibra em detergente neutro* & 76,5 & 15,6 & 34,0 & 54,6 \\
Fibra em detergente ácido* & 43,8 & 3,5 & 9,2 & 37,2 \\
Lignina* & 8,6 & 0,9 & 0,6 & 29,1 \\
Energia bruta (Mcal/kg) & 3,16 & 4,52 & 4,20 & 3,67 \\
\hline
\end{tabular}

*\% da matéria seca (MS).

Tabela 2. Participação dos ingredientes nas dietas experimentais e composição química das dietas caracterizadas pela substituição parcial do farelo de soja pelo farelo de mamona destoxificado

\begin{tabular}{lcccc} 
& \multicolumn{4}{c}{ Níveis de substituição (\%) } \\
\cline { 2 - 5 } Participação do ingrediente (\%) & 0 & 15 & 30 & 45 \\
\hline Feno de capim buffel & 40,0 & 40,0 & 40,0 & 40,0 \\
Milho em grão moído & 30,0 & 30,0 & 30,0 & 30,0 \\
Farelo de soja & 30,0 & 25,0 & 21,0 & 16,0 \\
Farelo de mamona destoxificado & 0,0 & 4,7 & 8,5 & 13,3 \\
Ureia & 0,0 & 0,3 & 0,5 & 0,7 \\
\hline Nutriente (\%) & & & & \\
Matéria seca \% & 91,0 & 91,1 & 92,2 & 92,2 \\
Matéria orgânica* & 85,1 & 84,7 & 85,5 & 85,2 \\
Matéria mineral* & 3,9 & 4,6 & 5,1 & 5,7 \\
Proteína bruta* & 20,6 & 20,6 & 20,4 & 20,5 \\
Extrato etéreo* & 3,4 & 3,4 & 3,5 & 3,6 \\
Carboidratos totais* & 72,1 & 71,4 & 71,0 & 70,2 \\
Carboidratos não fibrosos* & 26,6 & 24,6 & 23,9 & 22,4 \\
Fibra em detergente neutro* & 45,5 & 46,3 & 47,1 & 47,8 \\
Fibra em detergente ácido* & 21,2 & 22,3 & 23,4 & 23,8 \\
Lignina* & 3,9 & 5,2 & 6,3 & 7,7 \\
Energia bruta (Mcal/kg de MS) & 3,88 & 3,85 & 3,81 & 3,77 \\
\hline
\end{tabular}

*\% da matéria seca (MS). 
A avaliação da cinética da fermentação ruminal foi realizada pela técnica in vitro semiautomática de produção de gases proposta por Maurício et al. (2003). Um grama de amostra moída em moinho com crivos de $2 \mathrm{~mm}$ de diâmetro foi adicionado aos frascos de fermentação $(160 \mathrm{~mL})$ previamente injetados com $\mathrm{CO}_{2}$. Foram utilizados três frascos por tratamento. Frascos contendo somente líquido ruminal e meio de cultura (tampão) foram usados como controle.

O líquido ruminal utilizado como inóculo foi obtido de forma conjunta e homogeneizada de três bovinos machos adultos castrados da raça Sindi, providos de cânula ruminal. Os animais foram mantidos em dieta à base de capim buffel à vontade e $1 \mathrm{~kg} /$ dia de concentrado composto por farelo de milho, farelo de soja e ureia.

A pressão, em psi (pound per square inch), originada pelos gases acumulados na parte superior dos frascos foi medida por intermédio de um transdutor de pressão (tipo T443A, Bailey e Mackey, Inglaterra), conectado em sua extremidade a uma agulha $(0,6 \mathrm{~mm})$. As leituras de pressão foram feitas em maior frequência durante o período inicial de fermentação e reduzidas posteriormente $(2,4,6,8,9,11,12$, $14,17,20,24,28,34,48,72$ e $96 \mathrm{~h})$.

Os dados da produção cumulativa dos gases foram analisados pelo modelo bicompartimental citado em Schofield et al. (1994): $\mathrm{V}(\mathrm{t})=\mathrm{Vf} 1 /\left[1+\mathrm{e}^{(2-4 \mathrm{~m} 1(\mathrm{~L}-\mathrm{T})}\right]+\mathrm{Vf} 2 /\left[1+\mathrm{e}^{(2-4 \mathrm{~m} 2(\mathrm{~L}-\mathrm{T})}\right]$

Em que $V(t)$ representa o volume máximo total de gases produzidos; Vf1 representa o volume máximo de gás para a fração de rápida digestão (CNF); Vf2 representa o volume máximo de gás para a fração de lenta digestão $(\mathrm{CF}) ; m 1$ equivale à taxa de crescimento específico para a fração de rápida degradação; $m 2$ equivale à taxa de crescimento específico para a fração de lenta degradação; $L$ representa a duração dos eventos iniciais (fase de latência) de digestão, comum às duas fases; e o $T$ representa o tempo de fermentação.

A degradabilidade da MS foi estimada a partir da inserção de sacos de tecido não tecido (TNT) com amostras das dietas, gramatura de $100 \mathrm{mg} / \mathrm{cm}^{2}$, no interior dos frascos de fermentação, que foram retirados após $2,6,12$, 24, 48 e $96 \mathrm{~h}$ de incubação in vitro, e, posteriormente, secos em estufa a $105^{\circ} \mathrm{C}$ por $12 \mathrm{~h}$. $\mathrm{O}$ tempo de $\mathrm{Oh}$ foi obtido com a imersão dos sacos em água destilada a $37^{\circ} \mathrm{C}$ por 5 minutos.

Para a determinação da degradabilidade potencial, foi utilizado o modelo de Ørskov e Mcdonald (1979): DP $=\mathrm{a}+\mathrm{b}\left(1-\mathrm{e}^{\text {-ct }}\right)$, em que "DP" é a degradabilidade potencial; "a", a fração solúvel em água; "b”, a fração insolúvel em água, mas potencialmente degradável; "c", a taxa de degradação da fração (b); "t", o tempo de incubação em horas. A letra "e" é o log natural de (-ct). A degradabilidade efetiva (DE) foi calculada pela fórmula: $\mathrm{DE}=\mathrm{a}+(\mathrm{b} \times \mathrm{c}) /(\mathrm{c}+$ $\mathrm{k}$ ), em que "k" é a taxa de passagem. A taxa de produção de gases obtida pela técnica semiautomática de produção de gases $(m 1+m 2)$ foi utilizada para estimar a taxa de passagem $(\mathrm{k})$ (Mauricio et al., 2003) utilizada no ensaio de degradabilidade (Ørskov e Mcdonald, 1979).

Os parâmetros avaliados tiveram suas variâncias comparadas por contrastes ortogonais e regressão polinomial, com nível de significância de 5\%, utilizando-se os procedimentos GLM e REG. Os parâmetros dos modelos de produção de gases e degradabilidade ruminal foram estimados por procedimentos de regressão não linear (NLIN). As análises estatísticas foram realizadas por intermédio do programa computacional Statistical Analysis System (Versão 9.1, 2003).

Em relação às dietas, observou-se que apenas a taxa de produção de gases da fração fibrosa (m2) não foi influenciada pelos níveis de substituição do FS pelo FM (Tab. 3).

Por meio da avaliação das equações obtidas, pode-se perceber que os valores de produção cumulativa de gases dos carboidratos não fibrosos (Vf1), carboidratos fibrosos (Vf2) e totais (V) apresentaram comportamento quadrático de acordo com os níveis de substituição. Em inclusões de até $25 \%$, o Vf1 e o $\mathrm{V}$ obtiveram valores máximos de 174,7 e 237,8mL de gás/g de MS, respectivamente. Já a Vf2, nesse nível, obteve valor mínimo de $61,0 \mathrm{~mL}$ de gás/g de $\mathrm{MS}$, revelando menor aproveitamento da fração fibrosa pelos microrganismos; porém, a partir desse ponto, existe incremento na fermentação dessa fração. Esses eventos podem ser explicados, em parte, pela disponibilidade de carboidratos mais prontamente fermentáveis aos microrganismos 
ruminais com substituição do FS pelo FM até $25 \%$. Com maiores teores de FM, houve redução nessa disponibilidade, levando a microbiota fibrolítica a se desenvolver, incrementando a fermentação dos CF.

Tabela 3. Potencial máximo de produção de gases dos carboidratos não fibrosos (Vf1) e fibrosos (Vf2) em mL/g de MS, taxa de produção de gases dos carboidratos não fibrosos (m1) e fibrosos (m2) em $\mathrm{mL} / \mathrm{g}$ de MS/h, potencial máximo de produção de gases dos carboidratos totais (V), taxa de produção de gases total $(\mathrm{mT})$, fase de latência em horas e minutos (L) e o coeficiente de determinação $\left(\mathrm{R}^{2}\right)$ de dietas contendo substituições parciais do farelo de soja pelo farelo de mamona destoxificado

\begin{tabular}{lccccccc}
\hline \multirow{2}{*}{ Variáveis } & \multicolumn{3}{c}{ Níveis de farelo de mamona $(\%)$} & \multirow{2}{*}{$\mathrm{EP}^{(1)}$} & $\mathrm{R}^{2}$ & \multirow{2}{*}{$\mathrm{ER}^{(2)}$} \\
\cline { 2 - 5 } & 0 & 15 & 30 & 45 & & & \\
\hline $\mathrm{Vf}_{1}$ & 99,63 & 185,6 & 149,9 & 134,7 & 1,246 & 0,60 & $\hat{\mathrm{y}}=106,7+5,52 \mathrm{x}-0,112 \mathrm{x}^{2^{*}}$ \\
$\mathrm{Vf}_{2}$ & 92,77 & 56,38 & 72,77 & 69,83 & 1,970 & 0,45 & $\hat{\mathrm{y}}=89,17-2,02 \mathrm{x}+0,037 \mathrm{x}^{2^{*}}$ \\
$\mathrm{~m}_{1}$ & 0,0596 & 0,075 & 0,0678 & 0,0683 & 0,0010 & 0,45 & $\hat{\mathrm{y}}=0,061+0,0009 \mathrm{x}-0,00002 \mathrm{x}^{2^{*}}$ \\
$\mathrm{~m}_{2}$ & 0,0141 & 0,0140 & 0,0136 & 0,0135 & 0,0011 & - & $\hat{\mathrm{y}}=0,0138$ \\
$\mathrm{~V}$ & 192,4 & 241,98 & 222,7 & 204,5 & 1,807 & 0,76 & $\hat{\mathrm{y}}=195,5+3,6758 \mathrm{x}-0,0798 \mathrm{x}^{2^{*}}$ \\
$\mathrm{mT}$ & 0,0737 & 0,089 & 0,0814 & 0,0818 & 0,0008 & 0,42 & $\hat{\mathrm{y}}=0,075+0,0009 \mathrm{x}-0,00002 \mathrm{x}^{2^{*}}$ \\
$\mathrm{~L}$ & 6,28 & 7,15 & 6,87 & 6,89 & 0,195 & 0,60 & $\hat{y}=0,064 * \log _{\mathrm{e}}(\mathrm{x})+6,74^{*}$ \\
\hline
\end{tabular}

*Significativo $\mathrm{P}<0,05 .{ }^{(1)}$ Erro padrão da média. ${ }^{(2)}$ Equação de regressão com resposta linear ou quadrática, e equação exponencial.

A taxa de produção de gases dos carboidratos não fibrosos (m1) e dos carboidratos totais apresentaram comportamento quadrático com a substituição parcial do FS pelo FM. Houve incremento nos valores até 0,0711 e $0,0851 \mathrm{~mL} / \mathrm{g}$ de MS/h no nível de 22,5\%.

O tempo de colonização (L) foi incrementado pela inclusão do FM e obteve comportamento exponencial (Tab. 3). Esse fato pode ser explicado pela possível modificação da microbiota predominante no ambiente. Com o incremento do FM, houve um aumento nos teores de carboidratos de fermentação mais lenta, levando à maior multiplicação de microrganismos celulolíticos com características de tempo de colonização mais tardio.

Tabela 4. Fração solúvel em água (a), fração insolúvel em água, mas potencialmente degradável (b), taxa de degradação da fração "b" (c), coeficientes de determinação ( $\left.\mathrm{R}^{2}\right)$, degradabilidade potencial (DP), degradabilidade efetiva (DE) e taxa de passagem (k) obtidos na matéria seca (MS) das dietas contendo substituições parciais do farelo de soja pelo farelo de mamona destoxificado

\begin{tabular}{|c|c|c|c|c|c|c|c|}
\hline \multirow{2}{*}{ Variáveis } & \multicolumn{4}{|c|}{ Níveis de farelo de mamona $(\%)$} & \multirow{2}{*}{$\mathrm{EP}^{(1)}$} & \multirow{2}{*}{$\mathrm{R}^{2}$} & \multirow{2}{*}{$\mathrm{ER}^{(2)}$} \\
\hline & 0 & 15 & 30 & 45 & & & \\
\hline $\mathrm{a}, \% \mathrm{MS}$ & 34,4 & 33,7 & 33,4 & 33,6 & 0,647 & - & $\hat{y}=34,0$ \\
\hline $\mathrm{b}, \% \mathrm{MS}$ & 53,9 & 61,8 & 57,4 & 54,0 & 2,039 & - & $\hat{y}=54,6+0,538 x-0,0126 x^{2 *}$ \\
\hline $\mathrm{c}, \% / \mathrm{h}$ & 0,042 & 0,041 & 0,050 & 0,040 & 0,007 & - & $\hat{y}=0,043$ \\
\hline $\mathrm{DP}, \% \mathrm{MS}$ & 88,3 & 95,5 & 90,8 & 87,6 & 1,583 & 0,61 & $\hat{y}=89,0+0,478 x-0,012 x^{2^{*}}$ \\
\hline $\mathrm{DE}, \% \mathrm{MS}$ & 54,0 & 53,2 & 56,7 & 48,0 & 0,954 & 0,52 & $\hat{y}=53,2+0,298 x-0,0088 x^{2^{*}}$ \\
\hline $\mathrm{K}_{\mathrm{p}}, \% / \mathrm{h}^{(3)}$ & 0,0737 & 0,089 & 0,0805 & 0,0824 & 0,0008 & 0,42 & $\hat{y}=0,075+0,0008 x-0,005 x^{2 *}$ \\
\hline
\end{tabular}

*Significativo $\mathrm{P}<0,05 .{ }^{(1)}$ Erro padrão da média. ${ }^{(2)}$ Equação de regressão, teste de polinômio ortogonal, resposta linear, quadrática ou cúbica. ${ }^{(3)}$ Obtida pela taxa de produção de gases das frações de carboidratos. 
Perante análise dos parâmetros de degradabilidade ruminal da MS para as dietas, observa-se que os valores para os coeficientes (a) e (c) não foram diferentes estatisticamente entre os tratamentos testados, e apresentaram médias de $34,0 \%$ e $0,043 \% / h$, respectivamente.

Em relação ao coeficiente (b) da MS, foi observado comportamento quadrático, e, com a inclusão do FM até 21,3\%, houve aumentos nos valores até $60,34 \%$. Após esse ponto máximo, houve queda na degradação dessa fração, influenciada por níveis mais altos do FM e redução na disponibilidade dos nutrientes fermentáveis.

As degradabilidades potenciais (DP) e efetivas (DE) da MS dos tratamentos apresentaram comportamento quadrático em relação aos níveis de substituição do FS pelo FM. Em até 18,0\%, houve incremento nos valores da DP e DE, que alcançaram valores máximos de $93,7 \%$ e 55,7\%, respectivamente. Entretanto, com a substituição do FS pelo FM, ocorreu redução nessas variáveis da degradação, refletindo que, a partir desse nível, reduziu-se a disponibilidade dos nutrientes das dietas.

A substituição do farelo de soja pelo farelo de mamona destoxificado entre 15 e $30 \%$ incrementou a cinética de produção de gases e degradação ruminal in vitro. Ao se utilizar as equações de regressão obtidas, pode-se encontrar o ponto ideal de substituição in vitro em $25 \%$.

Palavras-chave: biodiesel, coproduto, fermentação, microiota

\begin{abstract}
The kinetics of gas production and in vitro ruminal degradation of diets contained replacement of soybean meal (SBM) by detoxicated castorbean meal (DCBM) (0, 15, 30 and $45 \%$ of substitution) were evaluated in this study. Values of gas production of non-fibrous carbohydrates (Vf1), fibrous carbohydrates (Vf2) and total carbohydrates (V) showed quadratic behavior, and by observation of equations can be obtained inclusions of 25\% the V and Vf1 obtained maximum values of 174.7 and 237.8 $\mathrm{ml}$ gas / g DM, respectively. The potential degradability (PD) and effective degradability (ED) of dry matter showed quadratic behavior and by observation of equations can be perceive that up to $18.0 \%$ there was an increase in the values of PD and ED that obtained maximum values of $93.7 \%$ and $55.7 \%$, respectively. The replacement of SBM by DCBM from 15 to $30 \%$ increased the kinetics of gas production and rumen degradation.
\end{abstract}

Keywords: biodiesel, byproduct, fermentation, microbiota

\section{REFERÊNCIAS}

ANANDAN, S; ANIL KUMAR, G.K.; GHOSH, J. et al. Effect of different physical and chemical treatments on detoxification of ricin in castor cake. Anim. Feed Sci. Technol., v.120, p.159168,2005

MAURÍCIO, R.M.; PEREIRA, L.G.R.; GONÇALVES, L.C. et al. Relação entre pressão e volume para a implantação da técnica in vitro semi-automática de produção de gases na avaliação de forrageiras tropicais. Arq. Bras. Med. Vet. Zootec., v.55, p.216-219, 2003.

MERTENS, D.R. Creating a system for meeting the fiber requirements of dairy cows. J. Dairy Sci., v.80, p.1463-1481, 1997.
NRC-NATIONAL RESEARCH COUNCIL, Nutrient Requirements of Small Ruminants. Washington, National Academy of Sciences. 362p. 2007.

OLIVEIRA, A.S.; CAMPOS, J.M.S.; OLIVEIRA, M.R.C. et al. Nutrient digestibility, nitrogen metabolism and hepatic function of sheep fed diets containing solvent or expeller castorseed meal treated with calcium hydroxide. Anim. Feed Sci. Technol., v.158, p.15-28, 2010a.

OLIVEIRA, A.S.; OLIVEIRA, M.R.C.; CAMPOS, J.M.S. et al. In vitro ruminal degradation of ricin and its effect on microbial growth. Anim. Feed Sci. Technol., v.157, p.4154, $2010 \mathrm{~b}$. 
ØRSKOV, E.R.; McDONALD, J. The estimation of protein degradability in the rumen from incubation measurements weighted according to rate of passage. J. Agric. Sci., v.92, p.499-503, 1979.

STATICAL Analysis System - SAS. Versão 13. Cary, NC, EUA, 2003.

SCHOFIELD, P.; PITT, R.E.; PELL, A.N. Kinetics of fiber digestion from in vitro gas production. J. Anim. Sci., v.72, p.2980-2991, 1994.
SEVERINO. L.S. O que sabemos sobre a Torta de mamona. Brasil: Embrapa Algodão, 2005. $31 \mathrm{p}$.

SILVA, D.J.S.; QUEIROZ, A.C. Análise de alimentos: métodos químicos e biológicos. Brasil: UFV, 2002. 235p.

SNIFFEN, C.J.; O CONNOR, J.D.; VAN SOEST, P.J. A net carboydrate and protein sistem for evaluating cattle diets: II. Carboydrate and protein avalability. J. Anim. Sci., v.70, p.3562-3577, 1992. 